\title{
The effects of a fat loss supplement on resting metabolic rate and hemodynamic variables in healthy females: preliminary results
}

\author{
Gina Zito, Bill Campbell, Ryan Colquhoun, Nic Martinez, Laura Buchanan, Matt Lehn, Mallory Johnson, \\ Courtney St Louis, Yasmin Smith, Brad Cloer, Allison Pingel \\ From The Eleventh International Society of Sports Nutrition (ISSN) Conference and Expo \\ Clearwater Beach, FL, USA. 20-21 June 2014
}

\section{Background}

Individuals looking to improve their physique may ingest thermogenic supplements for the purposes of elevating resting metabolic rate and ultimately induce fat loss. The purpose of this study was to examine the effects of a commercially available dietary supplement (containing ingredients that promote thermogenesis) on resting metabolic rate (RMR) and hemodynamic variables in a randomized, double-blind, placebo-controlled cross-over study.

\section{Methods}

10 female participants $(27.8 \pm 12.4$ years; $166.2 \pm 7.2 \mathrm{~cm}$; $61.7 \pm 8.0 \mathrm{~kg}$, and $22.4 \pm 2.8 \mathrm{BMI})$ volunteered to participate in this investigation. Participants underwent two different testing sessions separated by approximately 7 days. On their first visit, participants arrived to the laboratory after an overnight fast and underwent a baseline RMR, heart rate (HR), and blood pressure (BP) assessment. Following this, each participant ingested a dietary supplement (FitMiss Burn ${ }^{\mathrm{TM}}$ ) or a placebo and repeated the RMR, HR, and BP assessments at 60, 120, and 180 minutes post-ingestion. The thermogenic ingredients contained in the dietary supplement included caffeine, green tea extract, yohimbine $\mathrm{HCL}$, and other ingredients. The placebo was void of active ingredients known to elevate RMR. Approximately 1-week later, the alternative supplement was ingested and the assessments were repeated in the exact same manner. Data were analyzed via a 2-factor [2x4] within-subjects repeated measures analysis of variance (ANOVA) using SPSS version 22.0. Post-hoc tests were analyzed via paired samples t-tests. The criterion for significance was set at $\mathrm{p} \leq 0.05$. Consent to publish the results was obtained from all participants.

\section{Results}

The repeated measures ANOVA revealed a significance effect for time relative to the raw RMR data. Post-hoc analyses revealed that the dietary supplement demonstrated trends for significance at 60 minutes $(\mathrm{p}=0.088)$ post supplementation and significant elevations in RMR (kilocalories/day) at 2 and 3-hours post ingestion ( $\mathrm{p}=0.033$ and 0.017 , respectively) as compared to baseline RMR values.

Table 1 RMR (mean \pm SD kcals/day) and (\% increase in RMR as compared to baseline values) for each supplement group

\begin{tabular}{lllll}
\hline & Baseline & 60-minute & 120-minute & 180-minute \\
\hline FitMiss Burn $^{\text {TM }}$ & $1,422 \pm 221$ & $1,495 \pm 182(5.1 \%)^{\#}$ & $1,524 \pm 171(7.2 \%)^{*}$ & $1,526 \pm 189(7.3 \%)^{*}$ \\
\hline Placebo & $1,425 \pm 196$ & $1,464 \pm 173(2.7 \%)$ & $1,475 \pm 173(3.5 \%)$ & $1,512 \pm 198(6.1 \%)^{*}$ \\
\hline
\end{tabular}

\# - Post-hoc statistical trend compared to baseline values $(p \leq 0.10)$

* - Post-hoc statistical difference compared to baseline values ( $p \leq 0.05)$

\footnotetext{
* Correspondence: bcampbell@usf.edu University of South Florida, Tampa, Florida, USA
} 
The only elevation in the placebo treatment occurred at 3hour post supplementation $(\mathrm{p}=0.024)$ time point as compared to baseline RMR values. Table 1 demonstrates the raw data (mean $\pm \mathrm{SD}$ ) and the percentage increases in RMR for each time point for both supplement groups. Heart rate and blood pressure values did not change over the course of the 3-hour testing period for either group.

\section{Conclusions}

The dietary supplement treatment (FitMiss Burn ${ }^{\mathrm{TM}}$ ) experienced greater elevations in RMR values as compared to the placebo treatment. These elevations came with no adverse effects relative to resting heart rate and blood pressure values. Taken on a daily basis, FitMiss Burn $^{\mathrm{TM}}$ supplementation may increase overall energy expenditure possibly leading to reductions in fat mass over time.

\section{Acknowledgement}

This study was supported by an ISSN Educational Research Grant.

Published: 1 December 2014

doi:10.1186/1550-2783-11-S1-P1

Cite this article as: Zito et al:: The effects of a fat loss supplement on resting metabolic rate and hemodynamic variables in healthy females: preliminary results. Journal of the International Society of Sports Nutrition 2014 11(Suppl 1):P1.

Submit your next manuscript to BioMed Central and take full advantage of:

- Convenient online submission

- Thorough peer review

- No space constraints or color figure charges

- Immediate publication on acceptance

- Inclusion in PubMed, CAS, Scopus and Google Scholar

- Research which is freely available for redistribution

Submit your manuscript at www.biomedcentral.com/submit 